\title{
Avaliação da atividade antimicrobiana de ração para frango aditivada de nanopartículas de óxido de zinco
}

\author{
Evaluation of the antimicrobial activity of poultry feed additives with zinc oxide nanoparticles \\ Evaluación de la actividad antimicrobiana de alimento para pollos añadido con nanopartículas de \\ óxido de zinc
}

Recebido: 04/06/2021 | Revisado: 10/06/2021 | Aceito: 16/06/2021 | Publicado: 28/06/2021

Rosana da Silva

ORCID: https://orcid.org/0000-0002-0955-5630 Universidade Comunitária da Região de Chapecó, Brasil E-mail: rosanna@unochapeco.edu.br

Alícia Maziero Baretta

ORCID: https://orcid.org/0000-0001-5134-2180 Universidade Comunitária da Região de Chapecó, Brasil

E-mail: ali_baretta@unochapeco.edu.br

Luciano Luiz da Silva

ORCID: https://orcid.org/0000-0001-7771-0623 Universidade Comunitária da Região de Chapecó, Brasil E-mail: lucianols@unochapeco.edu.br

Raquel Zeni Ternus

ORCID: https://orcid.org/0000-0001-5159-4396 Universidade Comunitária da Região de Chapecó, Brasil

E-mail: razete@gmail.com

Gustavo Lopes Colpani

ORCID: https://orcid.org/0000-0002-6193-4611 Universidade Comunitária da Região de Chapecó, Brasil E-mail: g_colpani@unochapeco.edu.br

Márcio Antônio Fiori

ORCID: https://orcid.org/0000-0002-4292-2068 Universidade Comunitária da Região de Chapecó, Brasil

E-mail: fiori@unochapeco.edu.br

Francieli Dalcanton

ORCID: https://orcid.org/0000-0003-0065-1279 Universidade Comunitária da Região de Chapecó, Brasil E-mail: fdalcanton@unochapeco.edu.br

Micheli Zanetti

ORCID: https://orcid.org/0000-0001-5218-7522 Universidade Comunitária da Região de Chapecó, Brasil E-mail: eng.miche@unochapeco.edu.br

Josiane Maria Muneron de Mello

ORCID: https://orcid.org/0000-0002-0450-6426

Universidade Comunitária da Região de Chapecó, Brasil E-mail: josimello@unochapeco.edu.br

\begin{abstract}
Resumo
A presença de bactérias patogênicas como a Salmonella spp e o Staphylococcus aureus nos aviários resulta em enormes perdas econômicas, influenciando no desempenho e qualidade do frango de corte. Essas bactérias causam intoxicações alimentares devido ao consumo de alimentos contendo enterotoxinas termoestáveis produzidas por elas. Estudos mostram que os antibióticos utilizados na avicultura podem provocar reações alérgicas aos seres humanos além de elevar a resistência bacteriana ao tratamento. As nanopartículas de óxido de zinco, NPs-ZnO, têm sido estudadas devido ao seu excelente potencial antimicrobiano e pelo zinco ser reconhecido como substância segura para consumo em baixas concentrações. Além disso o zinco é um micronutriente metabolizado pelo organismo do frango e do ser humano, não sendo uma substância tóxica. Portanto este trabalho teve como objetivo agregar a propriedade antimicrobiana à ração para frango através da adição de NPs-ZnO e avaliar a atividade antibacteriana frente à bactérias Gram-negativas Salmonella Typhimurium e Gram-positivas Staphylococcus aureus. Foram avaliadas diferentes proporções das NPs$\mathrm{ZnO}$ na ração $\left(1,2,3,4\right.$ e 5\%, $\left.\mathrm{g} \mathrm{g}^{-1}\right)$, por meio de difusão em meio sólido, concentração inibitória mínima e curva de crescimento. Verificou-se que a concentração de $3 \%\left(\mathrm{~g} \mathrm{~g}^{-1}\right)$ das NPs-ZnO foi a concentração mínima necessária para evitar o crescimento das bactérias estudadas, podendo ser aplicada em ração para frango a fim de protegê-los de potenciais contaminações por bactérias patogênicas presente nas granjas.
\end{abstract}


Palavras-chave: Ração para frango de corte; NPs-ZnO; Atividade antibacteriana; Salmonella Typhimurium; Staphylococcus aureus.

\begin{abstract}
The presence of pathogenic bacteria such as Salmonella spp and Staphylococcus aureus in poultry houses results in huge economic losses, influencing the performance and quality of broiler chicken. These bacteria cause food poisoning due to the consumption of foods containing thermostable enterotoxins produced by them. Studies show that antibiotics used in poultry can cause allergic reactions to humans in addition to increasing bacterial resistance to treatment. Zinc oxide nanoparticles, NPs-ZnO, have been studied because of their excellent antimicrobial potential and because zinc oxide is recognized as a safe substance for consumption at low concentrations. In addition zinc is a micronutrient metabolized by the poultry organism and humans, not being a toxic substance. So the objective of this study was to add antimicrobial properties to poultry feed by the addition of NPs- $\mathrm{ZnO}$ and to evaluate antibacterial activity against Gramnegative Salmonella Typhimurium and Gram-positive Staphylococcus aureus bacteria. Different ratios of NPs-ZnO in the diet $\left(1,2,3,4\right.$ and $\left.5 \%, \mathrm{mg} \mathrm{g}^{-1}\right)$ were evaluated by solid diffusion, minimum inhibitory concentration and growth curve. It was found that the concentration of $3 \%\left(\mathrm{mg} \mathrm{g}^{-1}\right)$ of NPs- $\mathrm{ZnO}$ was the lowest necessary to prevent the growth of studied bacteria being able to be applied in poultry feed to protect them from potential pathogenic bacteria present in the farms.
\end{abstract}

Keyword: Feed for broiler poultry; NPs-ZnO; Antibacterial activity; Salmonella Typhimurium; Staphylococcus aureus.

\title{
Resumen
}

La presencia de bacterias patógenas como Salmonella spp y Staphylococcus aureus en los aviarios genera enormes pérdidas económicas que influyen en el rendimiento y la calidad del pollo de engorde. Estas bacterias provocan intoxicaciones alimentarias debido al consumo de alimentos que contienen enterotoxinas termoestables producidas por ellas. Los estudios demuestran que los antibióticos utilizados en la producción de pollo pueden provocar reacciones alérgicas en los seres humanos además de aumentar la resistencia bacteriana al tratamiento. Las nanopartículas de óxido de zinc, NPs-ZnO, han sido estudiadas por su excelente potencial antimicrobiano y porque el zinc es reconocido como una sustancia segura para el consumo en bajas concentraciones.Además, el zinc es un micronutriente metabolizado por el pollo y el organismo humano, y no es una sustancia tóxica. Por lo tanto, este trabajo tuvo como objetivo agregar la propiedad antimicrobiana a la alimentación de los pollos mediante la adición de NPs-ZnO y evaluar la actividad antibacteriana contra las bacterias Gram negativas Salmonella Typhimurium y Gram positivas Staphylococcus aureus. Se evaluaron diferentes proporciones de NPs-ZnO en la dieta $\left(1,2,3,4\right.$ y 5\%, $\left.\mathrm{mg} \mathrm{g}^{-1}\right)$ mediante difusión en medio sólido, concentración mínima inhibitoria y curva de crecimiento. Se encontró que la concentración de $3 \%\left(\mathrm{mg} \mathrm{g}^{-1}\right)$ de NPs-ZnO fue la concentración más baja necesaria para prevenir el crecimiento de las bacterias estudiadas, y se puede aplicar en la alimentación de los pollos para protegerlos de una posible contaminación por bacterias patógenas presentes en granjas.

Palabras clave: Alimento para pollos de engorde; NPs-ZnO; Actividad antibacterial; Salmonella Typhimurium; Staphylococcus aureus.

\section{Introdução}

A avicultura mundial se destaca entre as atividades do setor agropecuário com índices de produção em constante crescimento, e as atuais previsões globais afirmam que até 2025 a carne de frango terá o nível mais alto de produção e consumo, quando comparado a carne bovina, suína e ovina (OECD/FAO, 2016). No Brasil, a avicultura é uma importante atividade econômica devido ao reconhecimento da produção brasileira, as exportações dos produtos, bem como o alto índice de empregabilidade (Carvalho Júnior \& Giarola, 2020). Isso classifica o Brasil como um grande produtor de carne de frango e segundo dados da ABPA (Associação Brasileira de Proteína Animal), em 2020, a produção neste segmento foi de 13,845 milhões de toneladas, colocando o país na posição de terceiro maior produtor e maior exportador mundial, mantendo sua posição do ano anterior, conforme mostra o Relatório Anual da Associação Brasileira da Proteína Animal - ABPA (2021).

Um dos maiores problemas na avicultura, mesmo nas granjas mais modernizadas, é a presença de bactérias patogênicas, destacando-se a Salmonella spp, pois resultam em enormes perdas econômicas devido à alta mortalidade dos frangos, custos elevados com medicamentos e erradicação, perda de qualidade e, além disso, alguns sorotipos de Salmonella spp. são agentes causadores de enfermidades sistêmicas e gastroentéricas em seres humanos (Oliveira, et al., 2007; Boni, et al., 2011; Borges, et al., 2017; Tozzo, et al., 2018; Webber, et al., 2019). A salmonela é uma bactéria gram-negativa que está presente em muitas fontes de alimentos e faz parte da flora de certas espécies animais, como as aves. E mesmo sendo encontrada nos animais, como 
parte da flora natural, quando há um desequilíbrio, resulta em infecção intestinal severa que, muitas vezes, pode ser fatal ao animal. Para os seres humanos ela é um verdadeiro risco a saúde. Apesar de todos os cuidados que o produtor tem na propriedade e todas as situações para contenção da doença nos aviários brasileiros com uma indústria altamente especializada, os casos ainda são recorrentes no Brasil (Oliveira, et al., 2007; Strockbine, et al., 2015; Tozzo, et al., 2018; Antonelli, et al., 2019; Webber, et al., 2019).

Atualmente a forma utilizada para controlar os agentes patogênicos do trato gastrintestinal do frango de corte é a aplicação de antibióticos e outras preparações químicas presentes na ração. Porém o uso extensivo destes produtos promove à formação de microrganismos resistentes, gerando tratamentos não-efetivos (Amiranashvili, et al., 2016). Além de que o uso intensivo de antibióticos pode desencadear problemas potenciais à saúde humana, como toxicidade, alergia e resistência bacteriana, trazendo preocupações relacionadas à saúde pública (Costa Leite, et al., 2012; Maciel, Machado \& Avancini, 2019; Antonelli, et al., 2019).

Para manter-se no patamar de maior exportador, o Brasil tem buscado se adaptar às exigências internacionais, atendendo às legislações vigentes sobre as restrições do uso de antibióticos (Brasil, 2018). No Brasil, o Ministério da Agricultura Pecuária e Abastecimento - MAPA, publicou a Portaria n ${ }^{\circ}$ 171, de 13 de dezembro de 2018, que informa sobre a intensão de proibição de uso de antimicrobianos com a finalidade de aditivos melhoradores de desempenho de alimentos (Brasil, 2018). Alguns antibióticos já foram proibidos de serem adicionados em rações para frangos, como por exemplo, o cloranfenicol, tetraciclinas, sulfonamidas sistêmicas, penicilinas, nitrofuranos e sulfato de colistina (Brasil, 2009; Brasil, 2016), porém a Portaria $\mathrm{n}^{\circ} 171$ aponta outros possíveis de serem proibidos (Brasil, 2018). Assim, este setor de produção necessita de alternativas que mantenham bons resultados de desempenho e produtividade, e evitem a contaminação por microrganismos patógenos, tendo como resultado a produção de alimentos seguros e saudáveis para o consumo humano (Souza Santana, et al., 2011; Embrapa, 2018). Portanto, materiais antimicrobianos como extratos vegetais, óleos naturais e nanopartículas de óxidos metálicos, podem ser uma alternativa em substituição aos antibióticos utilizados atualmente em rações para frangos, visando manter os resultados de desempenho obtidos com os antibióticos e reduzindo a possibilidade de resistência bacteriana (Costa Leite, et al., 2012; El Asbahani, et al., 2015; Zanetti, et al., 2015; Piletti, et al., 2019).

Dentre os óxidos metálicos, compostos a base de zinco tem se mostrado eficientes quando usados como agentes antimicrobianos (Kirschner, et al., 2017; Capelezzo, et al., 2018). O zinco é um oligoelemento vital e benéfico aos seres humanos por ser um micronutriente metabolizado pelo corpo humano e embora encontrado em pequenas quantidades, desempenha uma variedade de funções em relação ao sistema imune, a divisão celular, fertilidade, manutenção e crescimento corporal (Balasubramanian, et al., 2015). Além disso apresenta capacidade de resistir a rigorosas condições de processamento, elevada área superficial em relação ao volume e propriedades químicas e físicas únicas, possuindo estabilidade material, atividade antimicrobiana e baixo custo (Moezzi, et al., 2012; Nafchi, et al., 2012; Khodja, et al., 2014; Akbar \& Kumar, 2014; Khezerlou, et al., 2018).

O óxido de zinco $(\mathrm{ZnO})$ é considerado um material atóxico e altamente seguro e é um dos compostos listados pela FDA (Food and Drug Administration) como GRAS (Generally recognized as safe) (Doumbia, et al., 2015; FDA, 2014), e graças as suas excelentes propriedades, como a antimicrobiana e antifúngica, é amplamente empregado nos mais diversos segmentos (Emamifar \& Mohammadizadeh, 2015; Beigmohammadi, et al., 2016; Esmailzadeh, et al., 2016), entre eles no setor de embalagens (Sung, et al., 2013; Capelezzo, et al., 2018), preservação de alimentos (Espitia, et al., 2012) e para aplicações na área médica (Mirza, et al., 2015; Thaya, et al., 2016; Xiang, et al., 2017; Khezerlou, et al., 2018).

Aplicações de nanotecnologias estão sendo estudadas para trazer grandes benefícios e para agregar valor aos produtos obtidos nas indústrias de alimentos (Rossi, et al., 2014; Sekhon, 2014). As nanopartículas apresentam suas propriedades de forma mais intensa mesmo em menor quantidade, quando comparado aos compostos tradicionais, devido à mudança na proporção 
superfície-volume (Perez, et al., 2012; Khezerlou, et al., 2018). Quanto a propriedade antimicrobiana, o aumento da área superficial de superfície destes materiais permite uma maior interação através das membranas celulares dos microrganismos, aumentando assim a capacidade de absorção e de migração dos compostos (Beigmohammadi, et al., 2016; Khezerlou, et al., 2018; Youssef \& El-Sayed, 2018). A atividade antimicrobiana das NPs-ZnO pode ser atribuída a mecanismos, como: a liberação de íons de zinco $\left(\mathrm{Zn}^{+2}\right)$; a interação das nanopartículas com a parede celular da bactéria danificando a integridade celular e a formação de espécies reativas de oxigênio, ROS (Reactive Oxidative Species) (Doumbia, et al., 2015; Jalal, et al., 2010; Kasemets, et al., 2009; Sirelkhatim, et al., 2015). Diversos pesquisadores têm demostrado que as NPs-ZnO apresentam potencial antimicrobiano frente a Escherichia coli, Staphylococcus aureus, Pseudomonas aeruginosa, Candida albicans, Salmonella entérica, S. Typhimurium, Aspergillus brasiliensis, Candida albicans e Penicillium notatum (Akbar \& Kumar, 2014; Busi, et al., 2016; Pasquet, et al., 2014; Rana \& Singh, 2016; Sahin, et al., 2017; Porto, et al.; 2017; Dobrucka \& Dugaszewska, 2016).

Dessa forma, agregar a propriedade antimicrobiana à ração para frango de corte, através da adição de nanopartículas de óxido de zinco, a fim de evitar a proliferação de bactérias indesejáveis, que podem estar presentes na ração disponível para o frango consumir, e assim protegendo-o na fase inicial que é a fase mais vulnerável a contaminação por bactérias patogênicas, se torna um desafio. Portanto o objetivo desta pesquisa foi obter uma ração para frango de corte na fase inicial com eficiente ação antibacteriana, frente a bactérias Gram-negativa, Salmonella Typhimurium, e Gram-positiva, Staphylococcus aureus, através da adição de nanopartículas de óxido de zinco e assim identificar a concentração ideal das NPs-ZnO que deve ser adicionada na ração para tal ação ser efetiva.

\section{Metodologia}

A pesquisa é classificada quanto à natureza aplicada, possuindo abordagem de natureza quantitativa. Quanto ao enfoque, consiste em uma pesquisa explicativa com procedimentos técnicos, classificada como estudo experimental (Pereira, et al., 2018).

\subsection{Material}

A ração, utilizada para a realização desta pesquisa, é uma mistura pronta, adquirida comercialmente, a qual é armazenada em uma embalagem plástica de $5 \mathrm{~kg}$ e com vida útil de três meses, com composição de acordo com a necessidade nutricional para a fase inicial do frango de corte. Dentre os micronutrientes a ração continha $40 \mathrm{mg} \mathrm{kg}{ }^{-1}$ de zinco em sua composição. Como aditivo antimicrobiano foram utilizadas nanopartículas de óxido de zinco, NPs-ZnO, cedidas pela Kher Chemical Research, e óxido de zinco, ZnO (marca Sigma-Aldrich, padrão PA). Os ensaios de atividade antimicrobiana foram realizados com cepas de bactérias padrão Gram-negativa e Gram-positiva, Salmonella Typhimurium ATCC 14028, e Staphylococcus aureus ATCC 25923, respectivamente.

\subsection{Caracterização morfológica das NPs-ZnO}

Uma amostra das nanopartículas de óxido de zinco, NPs-ZnO, foi analisada morfologicamente através da microscopia eletrônica de varredura com canhão de campo de emissão (MEV-FEG), a fim de verificar sua estrutura e determinar seu tamanho e formato. O ensaio morfológico foi realizado em um equipamento de MEV-FEG (modelo Tescan) no laboratório de polímerosLPOL da Universidade de Caxias do Sul - UCS.

\subsection{Análise microbiológica da ração para frango sem aditivo}

Para avaliar microbiologicamente a ração para frango utilizada, realizou-se a técnica de Contagem Padrão de Microrganismos Mesófilos Aeróbios Viáveis a $30^{\circ} \mathrm{C}$, conforme metodologia apresentada na ISO 4833:2013 e o ensaio de contagem de bolores e leveduras, pela técnica de Petrifilm, de acordo com a metodologia descrita pela AOAC- Official Method 
997. 02 (AOAC, 2019). Realizou-se a leitura do número de colônias que se desenvolveram na placa, com auxílio de um contador de colônias (marca Quimis, modelo 290/0), selecionando as placas que continham entre 30 e 300 colônias. Utilizou-se a Equação (1), conforme recomendado pela ISO 7218:2013 (ISO, 2013), para obter a concentração bacteriana na ração.

$$
N=\frac{\sum \mathrm{C}}{\mathrm{v} * 1,1 * \mathrm{~d}}
$$

Em que:

$$
\begin{aligned}
& \mathrm{N}=\text { Contagem de mesófilos }\left(\mathrm{UFC}^{-1}\right) ; \\
& \mathrm{C}=\text { Número de colônias contadas na placa (colônias); } \\
& \mathrm{v}=\text { Volume da amostra }(\mathrm{mL}) ; \\
& \mathrm{d}=\text { Diluição utilizada (adimensional); } \\
& \text { 1,1 = Fator de correção (adimensional). }
\end{aligned}
$$

\subsection{Caracterização microbiológica das NPs-ZnO}

As metodologias empregadas para determinar a atividade antimicrobiana dos aditivos NPs- $\mathrm{ZnO}$ e do $\mathrm{ZnO}$, e da ração sem aditivo e aditivadas com diferentes concentrações, frente às bactérias $S$. Typhimurium e $S$. aureus foram: Difusão em meio sólido a partir de orifício, teste de atividade antimicrobiana para materiais antimicrobianos determinado pela JIS Z 2801:2000 (JIS, 2000) e ISO 22196:2007 (ISO, 2007) e curva de crescimento, detalhados a seguir.

\subsubsection{Preparo dos inóculos}

As suspensões bacterianas ( $S$. Typhimurium e $S$. aureus), mantidas em ágar estoque e conservadas a aproximadamente $-16^{\circ} \mathrm{C}$, foram transferidas com auxílio de uma alça de semeadura estéril para tubos de caldo Brain Heart Infusion (BHI, marca Himedia) e mantidas por $24 \mathrm{~h}$ a $35^{\circ} \mathrm{C}$ em estufa bacteriológica (marca Quimis, modelo Q316m5). A concentração do inóculo foi padronizada em solução salina estéril ( $0,85 \%)$, comparando a turbidez do inóculo com o padrão 0,5 da escala de McFarland em espectrofotômetro (marca Bel photonics, modelo 1105). As amostras foram observadas no comprimento de onda de $625 \mathrm{~nm}$, em que para a absorbância variando de 0,08 a 0,10 , resulta numa suspensão contendo aproximadamente de 1 a $2 \times 10^{8} \mathrm{UFC} \mathrm{mL}^{-1}$ da referida bactéria.

\subsubsection{Difusão em meio sólido a partir de orifício dos aditivos utilizados (NPs-ZnO e ZnO) e da ração sem aditivo}

O teste de difusão em meio sólido a partir de orifício foi utilizado com o objetivo de verificar a atividade antibacteriana dos aditivos utilizados, NPs-ZnO e ZnO, antes de adicioná-los a ração. Esta técnica foi realizada a partir da metodologia descrita por Alves, et al. (2000), com algumas modificações e observando as recomendações do CLSI (2012). A concentração bacteriana de $10^{8} \mathrm{UFC} \mathrm{mL}^{-1}$ foi semeada, com o auxílio de swab estéril (marca Absorve), sobre as superfícies de placas de Petri estéril, de $90 \mathrm{~mm}$ de diâmetro, contendo Müeller-Hinton Agar (marca Merck). Em cada placa de petri, foram feitos, com auxílio de um molde estéril, três orifícios (poços) equidistantes, com diâmetro de $8 \mathrm{~mm}$, sendo depositado nestes os aditivos e a ração. Os resultados de atividade antibacteriana foram interpretados de acordo com a metodologia proposta por Alves, et al. (2000), com adaptações, em que para poços de $8 \mathrm{~mm}$ de diâmetro a interpretação se resumiu da seguinte forma: halo menor que $10 \mathrm{~mm} \mathrm{o}$ aditivo é considerado inativo, entre 10 e $13 \mathrm{~mm}$ - parcialmente ativo, entre 14 e $19 \mathrm{~mm}$ ativo e acima de $19 \mathrm{~mm}$ muito ativo. Através dos resultados obtidos fez-se o tratamento estatístico utilizando o software Statistica 7.0 (StatSoft@), através do teste de Tukey com 5\% de probabilidade $(\mathrm{p} \leq 0,05)$. 


\subsubsection{Determinação da atividade antimicrobiana através da curva de crescimento bacteriano da ração aditivada}

O ensaio para obtenção da curva de crescimento bacteriano foi realizado conforme metodologia descrita pela norma japonesa JIS Z 2801:2000 (JIS, 2000) e ISO 22196:2007 (ISO, 2007), com algumas modificações. Utilizou-se seis amostras da ração sem a presença das nanopartículas, designadas de amostra controle, sendo que, três destas amostras, foram utilizadas para medir as células viáveis imediatamente após a inoculação, ou seja, no tempo inicial $(0 \mathrm{~h})$, e as outras três amostras foram utilizadas para o tempo final, ou seja, 24 h após a inoculação. Utilizou-se três amostras da ração aditivada para cada concentração da NPs-ZnO (1, 2, 3, e 5\%) no tempo 24 h, designadas de amostras teste. As amostras foram preparadas em placas de petri estéril de $50 \mathrm{~mm}$ de diâmetro e $15 \mathrm{~mm}$ de altura, com área de $196,2 \mathrm{~mm}^{2}$. Nas seis amostras controle adicionou-se a ração esterilizada

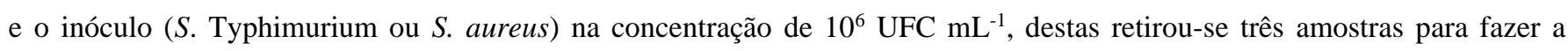
contagem de células no tempo $0 \mathrm{~h}$ e as demais incubou-se em estufa bacteriológica (marca Quimis, modelo 310/3) na temperatura de $35 \pm 1^{\circ} \mathrm{C}$ por $24 \mathrm{~h}$. Nas amostras da ração com as NPs-ZnO, adicionou-se $1 \mathrm{~g}$ de ração, as concentrações desejadas das NPs$\mathrm{ZnO}$, o inóculo e incubou-se da mesma forma. Imediatamente após a inoculação da bactéria, transferiu-se as três amostras controle, com auxílio de uma espátula estéril, para uma embalagem estéril, saco de stomacher (marca Nasco whirl-pak), e então adicionou-se $10 \mathrm{~mL}$ de água salina $0,85 \%$ e homogeneizou-se por aproximadamente $1 \mathrm{~min}$, esta amostra correspondeu a amostra $10^{\circ}$. Coletou-se com o auxílio de uma pipeta, $1 \mathrm{~mL}$ da amostra $10^{\circ}$, e transferiu-se para um tubo de ensaio contendo $9 \mathrm{~mL}$ de água salina $0,85 \%$, sendo esta a diluição $10^{-1}$. Repetiu-se este procedimento até completar 10 diluições seriadas, ou seja, até a diluição $10^{-10}$. Retirou-se $1 \mathrm{~mL}$ de cada diluição e dispensou-se em placas de petri em duplicata. Verteu-se $20 \mathrm{~mL}$ de ágar PCA, homogeneizou-se as placas e após a solidificação do meio, foram incubadas invertidas a $35 \pm 1^{\circ} \mathrm{C}$ por $48 \mathrm{~h}$ em estufa bacteriológica. Para as amostras controle e amostras teste, após incubação por $24 \mathrm{~h}$ à $35 \pm 1^{\circ} \mathrm{C}$ em estufa bacteriológica, realizouse o mesmo procedimento, adicionando $10 \mathrm{~mL}$ de água salina $0,85 \%$ e fez-se a contagem de células viáveis pelo método de placa. Após a incubação, realizou-se a contagem das placas que continham entre 30 e 300 colônias na série de diluições. Para cada amostra de teste, determinou-se o número de bactérias viáveis recuperadas em conformidade com a Equação (2):

$$
N=\frac{100 * C * D * v}{A}
$$

Onde:

$\mathrm{N}$ : é o número de células viáveis por $\mathrm{mm}^{2}$;

C: representa a contagem média de placa para as placas em duplicata (adimensional);

D: é o fator de diluição (adimensional);

A: Área superficial da amostra $\left(\mathrm{mm}^{2}\right)$

v: o volume de água estéril adicionada às amostras $(\mathrm{mL})$.

Através dos resultados obtidos para contagem de células viáveis, Equação (2), calculou-se o valor da atividade antimicrobiana de acordo com a Equação (3): (JIS Z 2801:2000).

$$
R=\left[\log \left(\frac{B}{A}\right)-\log \left(\frac{C}{A}\right)\right]=\left[\log \left(\frac{B}{C}\right)\right]
$$

Em que:

R: representa a atividade antimicrobiana (adimensional);

B: é a média do número de células viáveis da amostra controle (sem aditivo) após 24 h;

A: é a média do número de células viáveis imediatamente após a inoculação sobre a amostra controle (tempo 0 h) ;

C: é a média do número de células viáveis sobre a amostra teste (com aditivo) após 24 h.

O valor da atividade antimicrobiana obtida através desta norma não deve ser menor do que 2 para que o produto seja considerado como antimicrobiano (JIS Z 2801:2000). 


\subsubsection{Cinética da Curva de Crescimento}

Realizou-se o estudo de curva de crescimento para uma amostra da ração na concentração de $3 \%$ ( $\mathrm{mg} \mathrm{g}^{-1}$ ) das NPs-ZnO, nos tempos $0,12,24,36, \mathrm{e} 48 \mathrm{~h}$ frente as bactérias em estudo. O procedimento adotado foi o mesmo apresentado no item anterior, em que se preparou para cada tempo três amostras de ração sem as NPs-ZnO e três amostras com a concentração de NPs-ZnO de $3 \%\left(\mathrm{mg} \mathrm{g}^{-1}\right)$.

\section{Resultados e Discussão}

\subsection{Caracterização morfológica das NPs-ZnO}

A imagem de superfície das NPs-ZnO, obtida pelo microscópio eletrônico de varredura com canhão de campo de emissão (MEV-FEG), é apresentada na Figura 1 com ampliação de 100.000 vezes.

Figura 1 - Imagem obtida por microscopia eletrônica de varredura com canhão de campo de emissão (MEV-FEG) para o agente antimicrobiano NPs-ZnO com ampliação de 100k vezes.

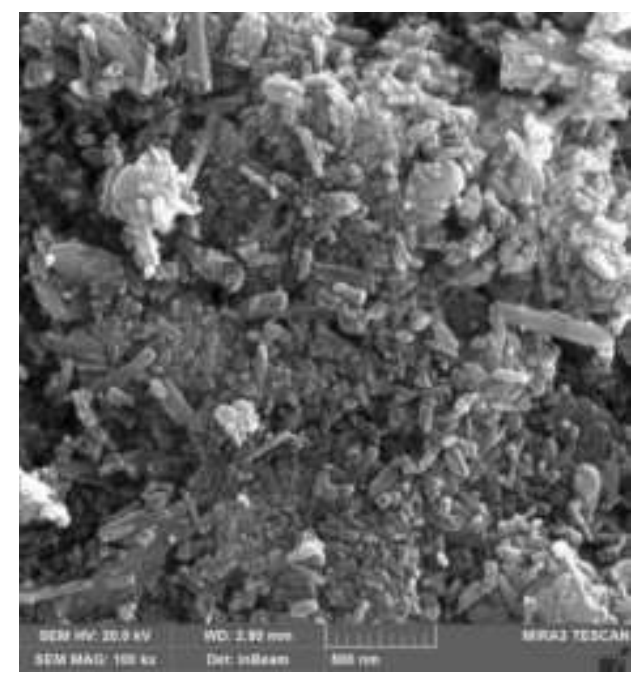

Fonte: Autores.

Através da Figura 1, verifica-se que as NPs-ZnO possuem formato de bastões com diâmetro médio de aproximadamente $20 \mathrm{~nm}$ e com diferentes comprimentos que podem atingir valores de até $100 \mathrm{~nm}$. Segundo a European Commission (2012) (European Food Safety Authority), qualquer nanomaterial é definido como um material produzido que seja composto por partes estruturais e funcionais discretas, que possuam mais de uma dimensão e cuja faixa de tamanho esteja entre $1 \mathrm{~nm}$ e $100 \mathrm{~nm}$. Portanto, pode-se dizer que o material utilizado na presente pesquisa está em escala nanométrica. Em algumas situações é possível observar a formação de pequenos aglomerados, que segundo Dantas, et al. (2016), refere-se à adesão das nanopartículas entre si por forças de atração fracas como as de Van der Waals, as quais são significativamente maiores em nanopartículas.

\subsection{Caracterização microbiológica da ração}

O resultado do ensaio microbiológico da ração para mesófilos aeróbios viáveis obtidos no presente estudo foi de

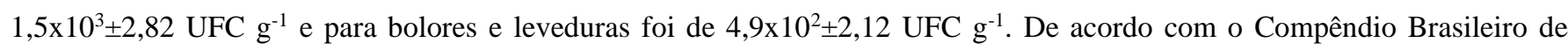
Alimentação Animal (Brasil, 2005) o limite de aceitabilidade para contagem de mesófilos e bolores e leveduras é $10^{3} \mathrm{UFC} \mathrm{g}^{-1} \mathrm{e}$ o inaceitável é acima de $10^{4} \mathrm{UFC} \mathrm{g}^{-1}$, assim a ração apresenta contagem de bolores e levedura dentro do limite aceitável, porém o resultado do ensaio microbiológico da ração para mesófilos aeróbios viáveis, apresentou valores acima do limite aceitável, ficando próximo do limite inaceitável. Este resultado pode indicar possíveis falhas em alguma etapa de produção da ração, seja 
na higienização, manipulação, desinfecção, controle de temperatura, armazenamento e/ou transporte (Santos, et al., 2010). Resultados semelhantes foram encontrados por Radziejewska, Stuper \& Szablewsk (2013), ao avaliar a qualidade de misturas alimentares de aves de capoeira do oeste da Polônia, sendo o valor médio de $3,0 \times 10^{3} \mathrm{UFC} \mathrm{g}^{-1}$ para mesófilos e para bolores e

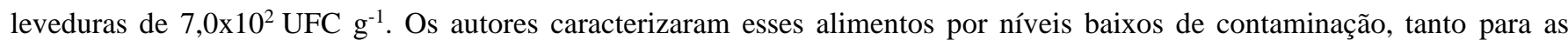
bactérias quanto para bolores e leveduras. Porém, de acordo com o Compêndio Brasileiro de Alimentação Animal (Brasil, 2005), o resultado de mesófilos obtido é superior ao limite especificado. Valores acima do padrão, indicam que a vida útil deste produto está comprometida, devido à deterioração causada pelos microrganismos presentes. Além disso, os frangos de corte ao consumir a ração ingerem os microrganismos mesófilos presentes, sendo potenciais veículos de contaminação ou deterioração. Carvalho, et al. (2005) comentaram que a maioria dos microrganismos encontrados nas aves são aeróbio mesófilos, sendo estas, constituídas principalmente por espécies de Enterobacteriaceae, Bacillus, Clostridium e Streptococcus, sendo bactérias patogênicas e deteriorantes. Diante disso, para realizar os demais ensaios microbiológicos, foi utilizado a ração esterilizada, para garantir que a ração não estivesse contaminada para não haver interferência nas análises.

\subsection{Caracterização microbiológica da NPs-ZnO e do ZnO}

O método de difusão em meio sólido a partir de orifício foi realizado para avaliar a atividade antimicrobiano das NPs$\mathrm{ZnO}$ e do ZnO. Na Figura 2 encontra-se os resultados para as NPs-ZnO frente à bactéria $S$. Typhimurium e $S$. aureus,

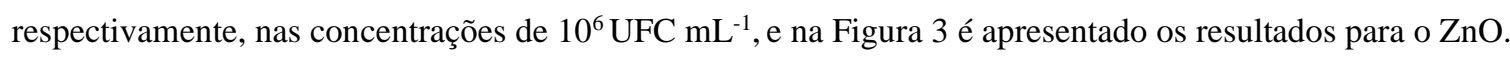

Figura 2 - Resultados microbiológicos do teste de difusão em meio sólido a partir de orifício para as NPs-ZnO frente as bactérias S. Typhimurium (a) e S. aureus (b), na concentração de $10^{6} \mathrm{UFC} \mathrm{mL}^{-1}$

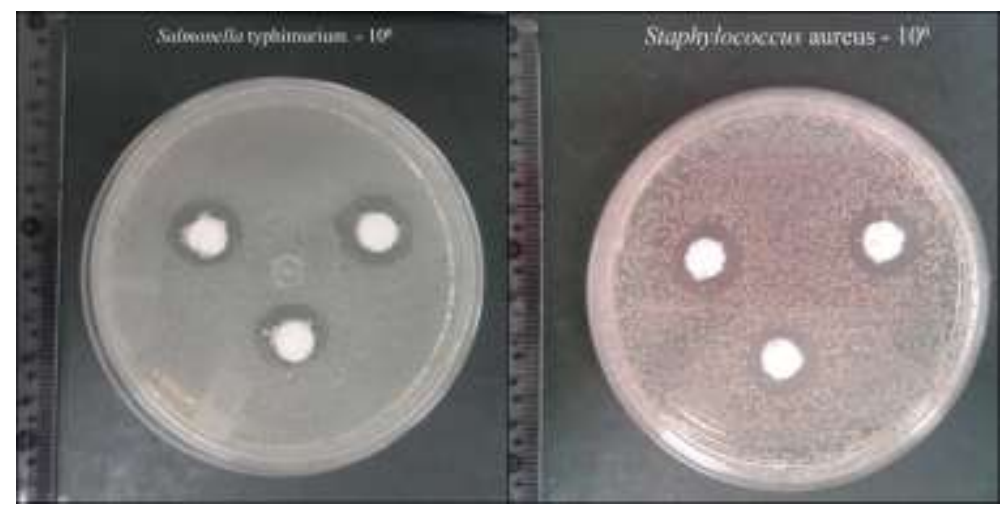

Fonte: Autores. 
Figura 3 - Resultados microbiológicos do teste de difusão em meio sólido a partir de orifício para ZnO frente as bactérias $S$. Typhimurium (a) e S. aureus (b) na concentração de $10^{6} \mathrm{UFC} \mathrm{mL}^{-1}$

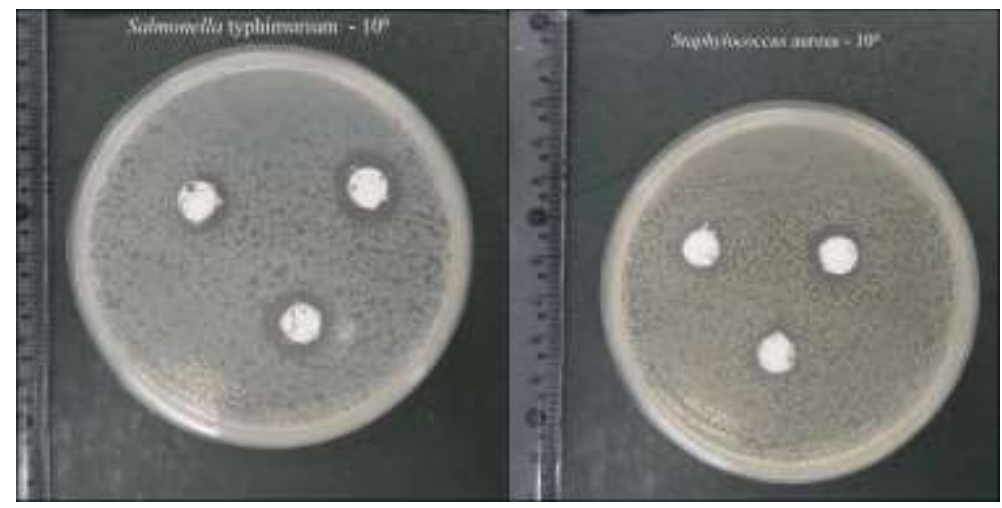

Fonte: Autores.

Através dos resultados expostos nas Figuras 2 e 3, é possível observar a zona de inibição que as NPs-ZnO e o ZnO produziram frente as bactérias avaliadas, $S$. Typhimurium e $S$. aureus, sendo que os valores médios de diâmetro de halo de inibição são apresentados na Tabela 1 .

Tabela 1 - Valores médios e desvio padrão amostral do diâmetro do halo de inibição a partir do teste de difusão em meio sólido para as NPs-ZnO e o $\mathrm{ZnO}$ frente a $S$. Typhimurium e $S$. aureus.

\begin{tabular}{ccc}
\hline Bactéria & $\begin{array}{c}\text { Valores médios do halo de inibição }(\mathrm{mm}) \\
\text { NPs-ZnO }\end{array}$ & ZnO \\
\hline S. Typhimurium & $16,33 \pm 0,58^{\mathrm{aA}}$ & $14,33 \pm 1,53^{\mathrm{bB}}$ \\
S. aureus & $15,00 \pm 0,00^{\mathrm{aA}}$ & $13,67 \pm 1,15^{\mathrm{bB}}$ \\
\hline *Letras maiúsculas iguais representam que não há diferenças significativas entre \\
$\begin{array}{l}\text { colunas e letras minúsculas iguais representam que não há diferenças significativas } \\
\text { entre linhas }(\mathrm{p}<0,05) \text {. Fonte: Autores. }\end{array}$
\end{tabular}

Através da Tabela 1 observa-se que as NPs-ZnO apresentam maiores halos de inibição para as bactérias em estudo, proporcionando atividade antimicrobiana mais intensa em comparação com partículas de $\mathrm{ZnO}$, demostrando que existe diferença significativa entre os dois aditivos avaliados. Além disso, levando em consideração o tamanho dos halos, é possível identificar que o agente antimicrobiano NPs-ZnO foi ativo frente a $S$. Typhimurium e $S$. aureus e o $\mathrm{ZnO}$ apresentou potencial antimicrobiano parcialmente ativo, conforme interpretação proposta por Alves, et al. (2000). Verifica-se que ZnO possui atividade antimicrobiana $15 \%$ inferior a obtida com as NPs-ZnO para S. Typhimurium e 10,5\% inferior para S. aureus, por este motivo é interessante utilizar o $\mathrm{ZnO}$ na forma nanométrica, pois suas propriedades intensificam-se trazendo maior funcionalidade e mais benefícios, devido a mudança que ocorre na proporção superfície-volume. Sendo que ao diminuir o volume com o tamanho, a proporção dos átomos na superfície das partículas aumenta, e, portanto, as propriedades de superfície sobrepõem às propriedades do material convencional, assim, uma quantidade pequena de nanopartículas fornece um nível de funcionalidade maior que, de outro modo, exigiria uma quantidade muito maior de material convencional (Perez, et al., 2012).

Da mesma forma, Espitia, et al. (2012) citam vários fatores que podem afetar a atividade antimicrobiana das NPs-ZnO, dentre elas o tamanho das nanopartículas e, portanto, a área de superfície, bem como sua atividade em sinergia com outros agentes antimicrobianos. Yamamoto (2001), também define que quanto menor o tamanho das nanopartículas, maior é a eficácia antimicrobiana, evidenciando os resultados obtidos na presente pesquisa. Para a ração sem o aditivo os resultados demostraram 
que a ração não apresentou atividade antibacteriana para as bactérias estudadas, pois não houve a formação de halo e, consequente inibição ou morte das bactérias, $S$. Typhimurium e $S$. aureus. Este resultado já era esperado visto que a ração não apresenta em sua composição aditivos antimicrobianos.

Observa-se também, na Tabela 1, que os maiores halos de inibição são observados para a bactéria $S$. Typhimurium, quando comparado com a bactéria S. aureus, demostrando que a S. Typhimurium é mais sensível aos aditivos quando comparado a S. aureus. Porém mesmo o halo de inibição ser maior para a S. Typhimurium, não houve diferença significativa entre ambas as bactérias estudadas. Este comportamento é explicado por Divya, et al. (2013) e Sahin, et al. (2017), que comentam que as NPs-ZnO causam a ruptura da membrana das bactérias provavelmente pela produção de espécies reativas de oxigênio, como superóxido e radicais hidroxilas (OH-). À medida que uma nanopartícula se aproxima da membrana, um potencial chamado zeta é gerado. As NPs-ZnO têm potencial zeta positivo na sua superfície tornando o meio mais ácido, gerando dano a membrana celular bacteriana e extrusão do conteúdo citoplasmático, resultando na morte da bactéria.

Os resultados microbiológicos do teste de difusão em meio sólido mostraram que as nanopartículas de óxido de zinco foram eficazes em inibir o crescimento bacteriano, mesmo para uma bactéria Gram-negativa (neste caso $S$. Typhimurium), que tende a ser mais resistentes quando comparada a uma bactéria Gram-positiva (neste caso $S$. aureus), pois elas possuem uma membrana adicional com uma estrutura de bicamada fosfolipídica, responsável pela proteção da membrana citoplásmica interior, em maior grau, o que promove maior resistência à essa classe de bactérias, enquanto que as células bacterianas gram-positivas, possuem apenas uma camada exterior, o que facilita a penetração de moléculas externas, promovendo a interação com a membrana citoplasmática e tornando-as mais frágeis quando comparadas às células bacterianas gram-negativas (Xie, et al. 2011; Bonilla \& Gárcia, 2012; Petchwattana, et al., 2016).

A Figuras 4 apresenta os resultados microbiológicos normalizados de curvas de crescimento para as bactérias $S$. Typhimurium e S. aureus, obtidos para a ração aditivadas com 1, 2, 3 e $5 \%$ de NPs-ZnO, para o tempo 0 e 24 h. Utilizou-se $1 \mathrm{~g}$ da ração para a realização do teste e uma concentração bacteriana de $10^{6} \mathrm{UFC} \mathrm{mL}^{-1}$. A ração pura, ou seja, sem adição do aditivo ( $0 \%$ de NPs-ZnO), também foi submetida ao teste, sendo este a contraprova (branco).

Figura 4 - Resultados da curva de crescimento para as bactérias $S$. Typhimurium e $S$. aureus obtidos com a ração aditivada com 1, 2, 3 e 5\% ( $\left.\mathrm{mg} \mathrm{g}^{-1}\right)$ de NPs-ZnO e para a ração sem a adição das NPs-ZnO. (a) S. Typhimurium e (b) S. aureus.
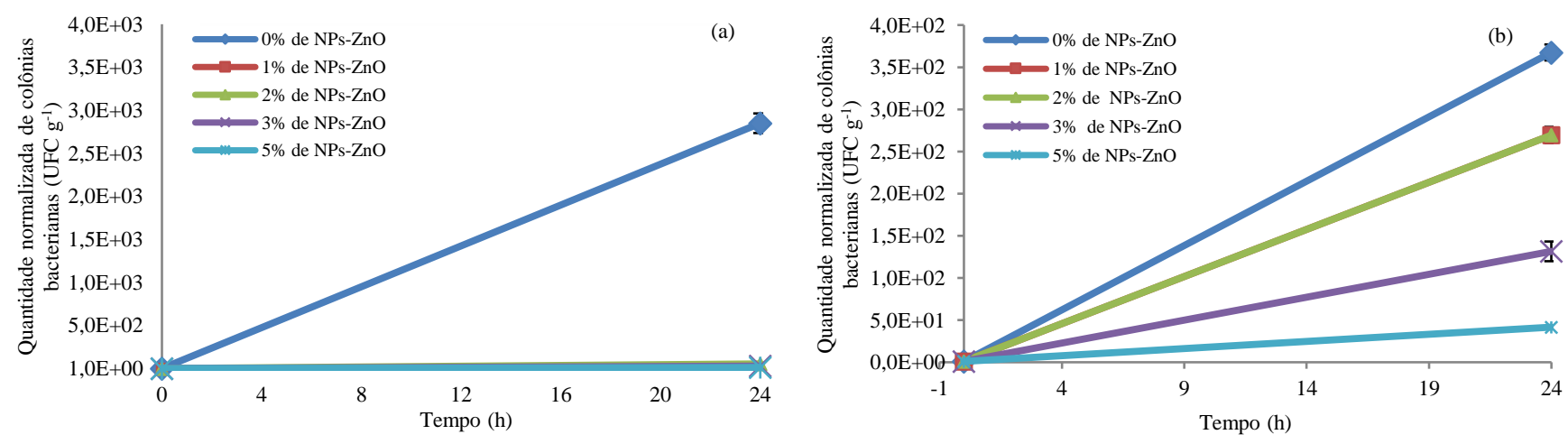

Fonte: Autores.

Através dos resultados apresentados na Figura 4(a), é possível observar que após 24 h de contato da ração aditivada com a $S$. Typhimurium, houve diminuição de $2 \log$ no crescimento da respectiva bactéria, utilizando-se as NPs-ZnO, para todas as concentrações testadas. Para a bactéria $S$. aureus, Figura a(b), após 24 h houve diminuição de 2 log da contagem de células para as concentrações de 3\% e 5\% de NPs-ZnO. 
A partir dos resultados de contagem de células, apresentados na Figura 4, pode-se determinar a concentração mínima para que as NPs-ZnO apresentassem atividade antimicrobiana, sendo que a JIS Z 2801:2000 determina que para o material apresentar eficiente atividade antimicrobiana deve-se eliminar pelo menos 2 logs da concentração bacteriana inicial após $24 \mathrm{~h}$ de contato. Assim os produtos que apresentarem atividade antimicrobiana igual ou superior a 2,0 possuem eficiente capacidade de inibir o crescimento de bactérias sendo aplicáveis como antimicrobianos (JIS Z 2801:2000). Na Tabela 2 é possível observar os resultados do valor da atividade antimicrobiana, calculados a partir da Equação 2, para as concentrações 0\%, 1\%, 2\%, 3\% e $5 \%$ das NPs-ZnO frente à $S$. Typhimurium e $S$. aureus.

Tabela 2 - Resultados do valor da atividade antimicrobiana para S. Typhimurium e S. aureus para as concentrações de $0 \%, 1 \%$, $2 \%, 3 \%$ e $5 \%$ de NPs-ZnO.

\begin{tabular}{ccc}
\hline $\begin{array}{c}\text { Concentração de } \\
\text { NPs-ZnO }(\%)\end{array}$ & $\begin{array}{c}\text { Valor da atividade antimicrobiana } \\
\text { para } S \text {. Typhimurium }\end{array}$ & $\begin{array}{c}\text { Valor da atividade antimicrobiana } \\
\text { para S. aureus }\end{array}$ \\
\hline $0 \%$ & $0,00 \pm 0,00^{\mathrm{a} \mathrm{A}^{*}}$ & $0,00 \pm 0,00^{\mathrm{aA}}$ \\
$1 \%$ & $1,41 \pm 0,01^{\mathrm{bB}}$ & $1,73 \pm 0,02^{\mathrm{bA}}$ \\
$2 \%$ & $1,91 \pm 0,04^{\mathrm{cB}}$ & $1,86 \pm 0,04^{\mathrm{cA}}$ \\
$3 \%$ & $1,99 \pm 0,01^{\mathrm{dB}}$ & $2,17 \pm 0,06^{\mathrm{dA}}$ \\
$5 \%$ & $2,32 \pm 0,03^{\mathrm{eB}}$ & $2,67 \pm 0,03^{\mathrm{eA}}$
\end{tabular}

*Letras maiúsculas iguais representam que não há diferenças significativas entre colunas e letras minúsculas iguais representam que não há diferenças significativas entre linhas $(\mathrm{p}<0,05)$. Fonte: Autores.

Através na análise estatística apresentada na Tabela 2, observa-se que houve diferença significativa na atividade antibacteriana entre as bactérias $S$. Typhimurium $e$ S. aureus, sendo que a atividade antimicrobiana foi maior para a bactéria $S$. aureus nas concentrações de 1\%, 3\% e 5\% de NPs-ZnO, quando comparada a $S$. Typhimurium. Esse comportamento deve-se possivelmente ao fato da bactéria $S$. aureus ser uma bactéria gram-positiva, logo possui apenas uma camada exterior como membrana plasmática, facilitando assim a difusão de materiais antimicrobianos no interior da célula, tornando-as mais susceptíveis a esses materiais, quando comparado as bactérias gram-negativas, neste trabalho $S$. Typhimurium (Shoja, et al., 2015). Ao avaliar as diferentes concentrações das NPs-ZnO testadas, verifica-se que também apresentaram diferença significativa na atividade antimicrobiana para todas as concentrações estudadas e para ambas as bactérias, $S$. Typhimurium e $S$. aureus. Portanto, ao seguir as determinações da JIS Z 2801:2000, pode-se dizer, pelos resultados da Tabela 2, que para a $S$. Typhimurium e para S. aureus, a condição de material antimicrobiano foi satisfeita para as concentrações de 3\% e 5\% das NPs$\mathrm{ZnO}$.

Assim, as NPs-ZnO podem ser aplicadas para agregar a propriedade antibacteriana em ração para frango. Resultados semelhantes foram obtidos por Akbar e Kumar (2014), que avaliaram a atividade antimicrobiana de NPs-ZnO em S. aureus e $S$. Typhimurium em uma concentração inicial de bactérias de $10^{6}$ e $10^{7} \mathrm{UFC} \mathrm{mL}^{-1}$, observaram redução em dois logs decimal após 24 h de incubação para ambas as bactérias. Sendo que não havia células de bactérias vivas de S. aureus após 6 dias de incubação, e após 8 dias para a $S$. Typhimurium. Os autores relataram, com a ajuda da micrografia eletrônica, que as nanopartículas têm alto impacto na integridade da superfície celular, e observaram também que a taxa de mortalidade celular aumentou com o passar do tempo de exposição entre as nanopartículas e as células bacterianas, devido ao efeito direto sobre a parede celular das bactérias causando à ruptura e morte celular. De acordo com os autores e com Sahin, et al. (2017), este comportamento é esperado, pois as NPs-ZnO produzem espécies reativas de oxigênio, como radicais hidroxila, superóxidos e peróxido de hidrogênio na presença 
de umidade, que reagem com a superfície celular das bactérias e causam danos à célula e aos conteúdos como proteínas, lipídios e DNA.

Com o objetivo de comparar a ação antibacteriana das NPs-ZnO com o $\mathrm{ZnO}$, realizou-se o procedimento de curva de crescimento para as bactérias $S$. Typhimurium e $S$. aureus, obtidos para a ração aditivadas com 1, 2, 3 e $5 \%$ ( $\mathrm{mg} \mathrm{g}^{-1}$ ) de $\mathrm{ZnO}$, para o tempo 0 e $24 \mathrm{~h}$. Utilizou-se $1 \mathrm{~g}$ da ração para a realização do teste e uma concentração bacteriana de $10^{6} \mathrm{UFC} \mathrm{mL}^{-1}$. A ração pura, ou seja, com $0 \%$ de $\mathrm{ZnO}$, também foi submetida ao teste, sendo esta a contraprova (branco). Os resultados são apresentados na Figura 5(a) para S. Typhimurium e Figura 5(b) para S. aureus.

Figura 5 - Resultados da curva de crescimento para a bactéria $S$. Typhimurium e $S$. aureus obtidos com a ração aditivadas com 1, 2, 3 e 5\% ( $\left.\mathrm{mg} \mathrm{g}^{-1}\right)$ de $\mathrm{ZnO}$ e para a ração sem a adição de $\mathrm{ZnO}$. (a) S. Typhimurium e (b) para S. aureus.
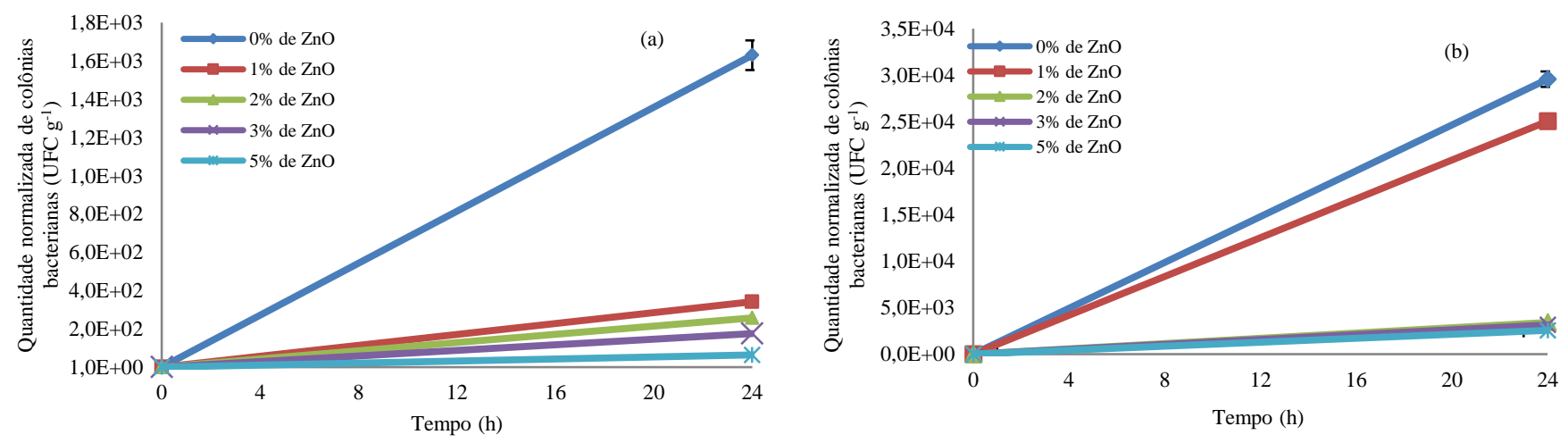

Fonte: Autores.

Conforme observado nos resultados demonstrados na Figuras 5(a) e 5(b), após 24 h de contato da ração aditivada com óxido de zinco e as bactérias em estudo, houve redução de um log tanto para $S$. Typhimurium quanto para $S$. aureus. Resultado inferior ao encontrado na presente pesquisa quando comparado a ração aditivada com as NPs-ZnO, sendo que em $24 \mathrm{~h}$ de interação, apresentaram dois $\log s$ de redução para as bactérias em estudo.

Tal resultado deve-se a maior área superficial que as NPs-ZnO possuem em comparação com o $\mathrm{ZnO}$, que é uma partícula convencional com menor área superficial (Hu \& Chen, 2008), dificultado a interação com as células dos microorganismos, e devido aos mecanismos de ação das NPs-ZnO que podem causar a ruptura da membrana das bactérias provavelmente pela produção de espécies reativas de oxigênio, como superóxido e radicais hidroxilas (Divya, et al., 2013; Akbar \& Kumar, 2014), e pela facilidade de interação das NPs-ZnO com a parede celular das bactérias, interferindo nos processos celulares dos micro-organismos (Janaki, Sailatha \& Gunasekaran, 2015).

De acordo com os resultados de contagem de células, encontrou-se a atividade antimicrobiana do $\mathrm{ZnO}$ através da Equação 2, e os resultados são apresentados na Tabela 3, bem como a análise estatística para interpretação dos resultados. 
Tabela 3 - Resultados do valor da atividade antimicrobiana das $\mathrm{ZnO}$ nas concentrações de 0\%, 1\%, 2\%, 3\% e 5\% frente as bactérias $S$. Typhimurium e $S$. aureus.

\begin{tabular}{ccc}
\hline $\begin{array}{c}\text { Concentração de } \\
\mathrm{ZnO}(\%)\end{array}$ & $\begin{array}{c}\text { Valor da atividade antimicrobiana } \\
\text { do } \mathrm{ZnO} \text { para S. Typhimurium }\end{array}$ & $\begin{array}{c}\text { Valor da atividade antimicrobiana } \\
\text { do } \mathrm{ZnO} \text { para } S . \text { aureus }\end{array}$ \\
\hline $0 \%$ & $0,00 \pm 0,00^{\mathrm{aA}}$ & $0,00 \pm 0,00^{\mathrm{aA}}$ \\
$1 \%$ & $0,68 \pm 0,01^{\mathrm{bA}}$ & $0,07 \pm 0,01^{\mathrm{bB}}$ \\
$2 \%$ & $0,80 \pm 0,02^{\mathrm{cA}}$ & $0,94 \pm 0,02^{\mathrm{cB}}$ \\
$3 \%$ & $0,97 \pm 0,04^{\mathrm{dA}}$ & $0,97 \pm 0,01^{\mathrm{cA}}$ \\
$5 \%$ & $1,40 \pm 0,04^{\mathrm{eA}}$ & $1,06 \pm 0,01^{\mathrm{dB}}$ \\
\hline
\end{tabular}

*Letras maiúsculas iguais representam que não há diferenças significativas entre colunas e letras minúsculas iguais representam que não há diferenças significativas entre linhas $(\mathrm{p}<0,05)$. Fonte: Autores.

Verifica-se, através da Tabela 3, que houve diferença significativa no valor da atividade antimicrobiana do $\mathrm{ZnO}$ entre as bactérias $S$. Typhimurium $e S$. aureus para as concentrações de 1,2 e 5\%, assim, apenas não apresentou diferença significativa na atividade antimicrobiana para a concentração de $3 \%$ de $\mathrm{ZnO}$, obtendo resultado semelhante para ambas as bactérias. Quando comparado as diferentes concentrações, observou-se que houve diferença significativa na atividade antimicrobiana entre as concentrações de 1,2, 3 e 5\% de $\mathrm{ZnO}$ testadas, para $S$. Typhimurium, e para $S$. aureus não houve diferença entre as concentrações 2 e 3\% do ZnO. Com esses resultados e com base nas recomendações da JIS Z 2801:2000, pode-se dizer que o ZnO não é considerado um eficiente agente antimicrobiano, pois o valor da atividade antimicrobiana obtido tanto para $S$. Typhimurium quanto para $S$. aureus foram inferiores a $2 \operatorname{logs}$ para as concentrações de 1, 2, 3 e $5 \%$.

Com base nos resultados obtidos, buscou-se avaliar a cinética de crescimento bacteriano da ração para frango de corte aditivada com 3\% de NPs-ZnO, sendo está foi a menor concentração que apresentou eficiência antimicrobiana pelo método da JIS Z 2801:2000 e a ISO 22196:2007. Utilizou-se a concentração bacteriana de $S$. Typhimurium e $S$. aureus de $10^{6} \mathrm{UFC} \mathrm{mL}^{-1} \mathrm{e}$ avaliou-se a ação antimicrobiana das NPs-ZnO nos tempos 0, 12, 24, 36, e 48 h. Os resultados são apresentados na Figura 6(a) para a bactéria $S$. Typhimurium e Figura 6(b) para a bactéria $S$. aureus. A Figura 6 apresenta também o resultado da curva de crescimento para ração sem o aditivo (0\% de NPs-ZnO).

Figura 6 - Resultado da cinética de crescimento das bactérias $S$. Typhimurium e $S$. aureus em ração para frango de corte aditivada com $0 \%$ e $3 \%$ de NPs-ZnO nos tempos $0,12,24,36$, e 48 h. (a) S. Typhimurium e (b) S. aureus.
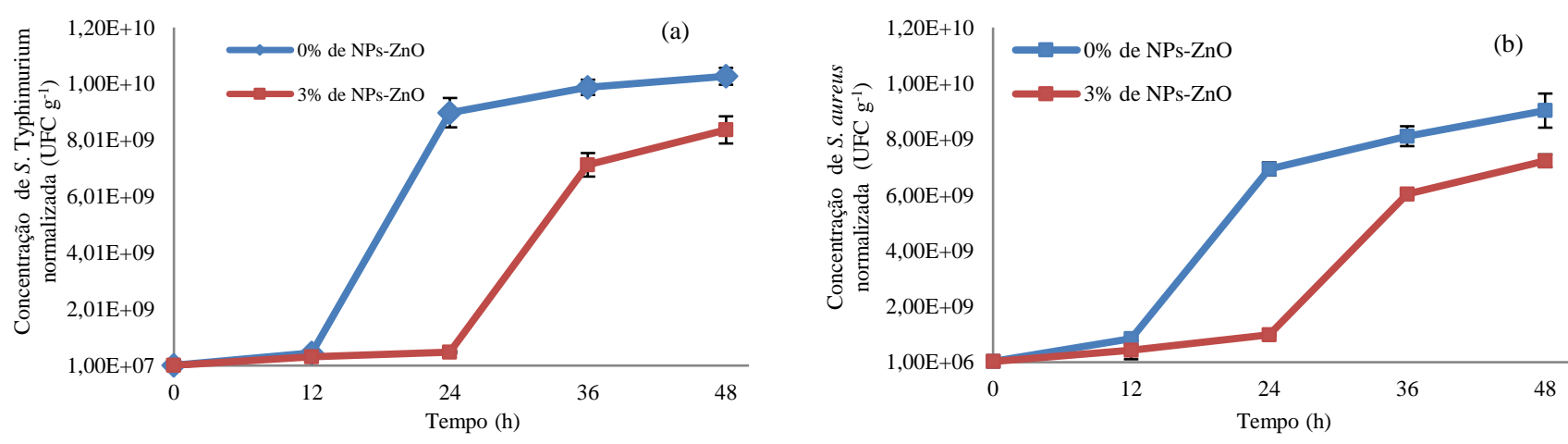

Fonte: Autores.

É possível observar através da Figura 6(a) o comportamento da S. Typhimurium na ração aditivada com 3\% de NPs$\mathrm{ZnO}$ e na ração sem as NPs-ZnO, sendo que na ração sem as NPs-ZnO, a linha de tendência gerada possui melhor definição das 
fases de crescimento celular, apresentando fase $L a g$ de adaptação até aproximadamente $12 \mathrm{~h}$, a fase $\log$ de crescimento celular, de 12 h até 24 h e de 24 h a 48 h a fase estacionária de crescimento celular. Para a ração aditivada a fase Lag foi até 24 h, de $24 \mathrm{~h}$ a $36 \mathrm{~h}$ a fase $\log$ e uma tendência a fase estacionária de $36 \mathrm{~h}$ até $48 \mathrm{~h}$, sendo que nesta fase é possível verificar para a ração aditivada que houve uma diminuição da fase Log, em comparação com a ração sem as NPs-ZnO (branco), e consequentemente menor crescimento de células devido à ação antimicrobiana das NPs-ZnO, resultado em uma diminuição de um log em $48 \mathrm{~h}$ de contato.

O mesmo comportamento foi observado na Figura 6(b), para S. aureus, sendo que, a fase Log iniciou após as 12 h de fase de adaptação, e permaneceu até as $24 \mathrm{~h}$, onde as células começam a estabilizar, ou seja, o $S$. aureus apresentou menor tempo de fase $L o g$ em comparação a $S$. Typhimurium, e menor concentração de células, com redução de um $\log$ em 48 h. Portanto as NPs-ZnO apresentaram maior ação antimicrobiana frente à bactéria $S$. aureus em comparação com a $S$. Typhimurium.

Situação semelhante foi encontrado por Aanchal, et al. (2013), ao estudarem os micro-organismos S. aureus e B. subtilis representando as bactérias Gram-positivas, e as cepas E. coli e A. aerogenes representando as bactérias Gram-negativas, para verificar o efeito das NPs-ZnO sobre o crescimento destas. Através das curvas de crescimento os autores observaram que para a amostra controle, sem a NPs-ZnO, apresentou as quatro fases, Lag, Log, estacionária e de morte, bem definidas. Já para S. aureus na presença da NPs-ZnO $\left(50 \mu \mathrm{g} \mathrm{mL}^{-1}\right)$, observou-se uma fase prolongada Lag indicando que ocorreu um atraso no crescimento de $S$. aureus. Isto ocorreu também para as demais concentrações estudadas de 100, 150 e $200 \mu \mathrm{g} \mathrm{mL}^{-1}$. Para E.coli a uma concentração de $400 \mu \mathrm{g} \mathrm{mL}^{-1}$, a fase $\operatorname{Lag}$ e a fase $\log$ foram alteradas e ocorreu uma diminuição na concentração de células. No caso de A. aerogenes não houve diferença de crescimento com concentrações abaixo de $400 \mu \mathrm{g} \mathrm{mL}^{-1}$. Segundo os autores, este perfil pode estar relacionado à estrutura celular de cada bactéria, pois verificou-se que as bactérias Gram-positivas são mais sensíveis do que as bactérias Gram- negativas para NPs-ZnO. Espitia, et al. (2013) comentaram que a diferença de susceptibilidade entre bactérias Gram-positivas e Gram-negativas pode ser devido a alterações nos mecanismos de interação das NPs-ZnO com a membrana bacteriana, pois as bactérias gram-positivas têm uma espessa parede celular, composta por peptidoglicano, em comparação com bactérias gram-negativas, os quais possuem uma membrana adicional com uma estrutura de bicamada fosfolipídica, o que resulta numa maior resistência a danos da membrana induzida por NPs-ZnO.

Em relação à toxicidade das NPs-ZnO, estudos realizados por Sharma, et al. (2012), avaliaram a toxicidade oral sub-

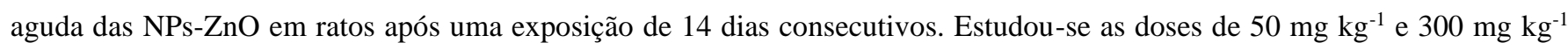
através de teste cometa para verificar o dano de DNA oxidativo e teste TUNEL para detectar as células apoptóticas no fígado. Os resultados revelaram que as NPs-ZnO, a uma dose mais elevada (300 $\mathrm{m} \mathrm{kg}^{-1}$ ), acumulam-se no fígado e causam estresse oxidativo levando ao dano do DNA e a apoptose no fígado. Contudo, nenhum dano significativo ao DNA e as células do fígado foi observado nos camundongos administrados com a menor dose de $\mathrm{NPs}-\mathrm{ZnO}\left(50 \mathrm{mg} \mathrm{kg}^{-1}\right)$. Sendo assim, as concentrações de $3 \%$ e 5\% estudadas na presente pesquisa estão de acordo com o estudo realizado por Sharma, et al. (2012), não apresentando toxicidade.

\section{Conclusão}

De acordo com as determinações da JIS Z 2801:2000 e ISO 22196:2007, onde o valor da atividade antimicrobiana deve ser igual ou superior a 2,0, foi possível identificar através do ensaio de curva de crescimento, que para a $S$. Typhimurium e para S. aureus a condição de eficiência antimicrobiana foi satisfeita para as concentrações de 3\% e 5\% das NPs-ZnO. Já o ZnO apresentou resultados inferiores a 2,0 não sendo considerado um eficiente antimicrobiano, nas concentrações avaliadas, pelo método da JIS Z 2801:2000 e a ISO 22196:2007.

De acordo com o conjunto dos resultados obtidos no presente estudo, determinou-se a menor concentração de $3 \%$ (30 $\mathrm{mg} \mathrm{g}^{-1}$ ) de NPs-ZnO com eficiente atividade antimicrobiana frente a $S$. Typhimurium e S. aureus. Assim, as NPs-ZnO apresentam 
potencial de aplicação em ração para frango de corte na fase inicial, para agregar à propriedade antimicrobiana, evitar à proliferação de micro-organismos indesejáveis na ração e assim proteger o frango de corte de potenciais contaminações por micro-organismos patogênicos como $S$. Typhmurium e $S$. aureus. Além disso, as concentrações de NPs-ZnO testadas, não são consideradas tóxicas, podendo ser utilizadas na nutrição do frango de corte, sem haver possibilidade de permanência de resíduos tóxicos na carne de frango, resultando em um produto saudável para o consumidor final.

Sugere-se para trabalhos futuros realizar análise de vida útil da ração aditivada com as NPs-ZnO, realizar ensaio in vivo para identificar o comportamento das NPs-ZnO no organismo do frango de corte e avaliar a ação antimicrobiana das NPs-ZnO frente a outros micro-organismos de interesse em alimentos.

\section{Agradecimentos}

Os autores agradecem à Unochapecó pela estrutura disponibilizada, à FAPESC/SC, CAPES/CNPq e PIBIC/CNPq pelo suporte financeiro, fundamentais para a realização da pesquisa.

\section{Referências}

Aanchal, J., Richa B., \& Pankaj, P. (2013). Probing interaction of Gram-positive and Gram-negative bacterial cells with ZnO nanorods. Materials Science and Engineering: C, 33 (3), 1247-1253. http://dx.doi.org/10.1016/j.msec.2012.12.019.

ABPA. Associação Brasileira de Proteína Animal. (2021). Relatório Anual 2021. http://abpa-br.com.br/storage/files/relatorio-anual-2020.pdf.

Akbar, A., \& Kumar, A. A. (2014). Zinc oxide nanoparticles loaded active packaging, a challenge study against S. Typhimurium and Staphylococcus aureus in readyto- eat poultry meat. Elsevie-Food Control, 38, 88-95. http://dx. doi.org/10.1016/j.foodcont.2013.09.065.

Alves, T. M. A., Silva, A. F., Brandão, M., Grandi, T. S., Smânia, E. F., Smânia, Jr. A., \& Zani, C. L. (2000). Biological screening of Brazilian medicinal plants. Mem. Inst. Oswaldo Cruz, 95 (3), 367-373. http://dx. doi.org/10.1590/S0074-02762000000300012.

Amiranashvili, L. L., Gagelidze, N. A., Varsimashvili, K. I., Tinikashvili, L. M., Tolordava, L. L., Gamkrelidze, M. D., Amashukeli, N. V., \& Makaradze, L. A. (2016). Antimicrobial susceptibility and antibiotic resistance profiles of cultivable lactic acid bacteria from intestinal tract of domestic chickens collected in Adjara. Annals of agrarian science, 14 (3), 182-186. http://dx. doi.org/10.1016/j.aasci.2016.08.001.

Antonelli, P., Belluco, S., Mancin, M., Losasso, C., \& Ricci, A. (2019). Genes conferring resistance to critically important antimicrobials in Salmonella enterica isolated from animals and food: A systematic review of the literature, 2013-2017. Research in Veterinary Science, 126, 59-67. http://doi: 10.1016/j.rvsc.2019.08.022.

AOAC, Official Method 997. 02. (2019). Yeast and mold counts in foods dry rehydratable film (Method Petrifilm tm). Official Method of Analysis, 21 st Edition, 2019, Chapter 17, p. 19-21.

Balasubramanian, P., Strobel, L. A., Kneser, U., \& Boccaccini, A. R. (2015). Zinc-containing bioactive glasses for bone regeneration, dental and orthopedic applications. Biomedical Glasses, 1, 51-69. https://doi.org/10.1515/bglass-2015-0006.

Beigmohammadi, F., Peighambardoust, S. H., Hesari, J., Azadmard-Damirchi, S., Peighambardoust, S. J., \& Khosrowshahic, N. K. (2016). Antibacterial properties of LDPE nanocomposite films in packaging of UF cheese. LWT Food Science and Technology, 65, 106-111. https://doi.org/10.1016/j.1wt.2015.07.059.

Boni, H. F. K., Carrijo, A. S., \& Fascina, V. B. (2011). Ocorrência de Salmonella spp. em aviários e abatedouro de frangos de corte na região central de Mato Grosso do Sul. Revista Brasileira de Saúde e Produção Animal, 12 (1), 84-95.

Bonilla, A. M. \& García, M. F. (2012). Polymeric materials with antimicrobial activity. Progress in Polymer Science, 37, 281- 339. https://doi.org/10.1016/j.progpolymsci.2011.08.005.

Borges, K., Furian, T., Gehlen, S. S., Tondo, E. C., Streck, A., Salle, C., Moraes. H. S., \& Nascimento, V. P. (2017). Spread of a major clone of Salmonella Enteritidis in poultry and in salmonellosis outbreaks in southern Brazil. Journal of Food Protection, 80, 158-163. http://dx.doi:10.4315/0362-028X.JFP-16-299.

Brasil, Ministério da Agricultura, Pecuária e Abastecimento/Secretaria de Defesa Agropecuária. (2018). Portaria n 171 , de 13 de dezembro de 2018. BRASIL. http://www.in.gov.br/materia/-/asset_publisher/Kujrw0TZC2Mb/content/id/55878469/do1-2018-12-19-portaria-n-171-de-13-de-dezembro-de-2018-55878239.

Brasil, Ministério da Agricultura e Abastecimento. (2005). Sindicato Nacional da Indústria de Alimentação Animal. Associação Nacional dos Fabricantes de Rações. Compêndio brasileiro de alimentação animal. São Paulo: ANFAR/CBNA/SDR, p. 204.

Brasil, Ministério da Agricultura, Pecuária e Abastecimento - MAPA. INSTRUÇÃO NORMATIVA No 45, DE 22 DE NOVMBRO DE 2016. Brasil, 2016. https://www.in.gov.br/materia/-/asset_publisher/Kujrw0TZC2Mb/content/id/22078290/do1-2016-11-30-instrucao-normativa-n-45-de-22-de-novembro-de2016-22078259.

Brasil, Ministério da Agricultura, Pecuária e Abastecimento (MAPA). INSTRUÇÃO NORMATIVA No 26, DE 9 DE JULHO DE 2009. (2009). Regulamento técnico para a fabricação, o controle de qualidade, a comercialização e o emprego de produtos antimicrobianos de uso veterinário. Brasil. http://www.agricultura.gov.br/animal/alimentacao/aditivos/aditivos-autorizadossso. 
Busi, S. Rajkumari, J., Pattnaik, S., Parasuraman, P., \& Hnamte, S. (2016). Extracellular synthesis of zinc oxide nanoparticles using acinetobacter schindleri siz7 and its antimicrobial property against foodborne pathogens. Journal Microbiology, Biotechnology and Food Sciences, 5 (5), 407-411. https://doi.10.15414/JMBFS.2016.5.5.407-411.

Capelezzo, A. P., Mohr, L. C., Dalcanton, F., Barreta, C. R. D. M., Martinsi, M. A. P. M., Fiori, M. A., \& Mello, J. M. M. (2018). Antimicrobial biodegradable polymer through additivation with zinc based compounds. Química Nova, 41 (4), 367-374. http://dx.doi.org/10.21577/0100-4042.20170187.

Carvalho Júnior, L.C., \& Giarola, P.C.M. (2020). Um retrato da cadeia produtiva de carne avícola em Santa Catarina e no Brasil no início do século XXI. Revista Americana de Empreendedorismo e Inovação, 2 (2), 141-150.

Carvalho, A. C. F. B., Cortez, B. M., Salotti, K. P., Bürger, A. M. C., \& Vidal-Martins. (2005). Presença de microrganismos mesófilos, psicrotróficos e coliformes em diferentes amostras de produtos avícolas. Arquivos do Instituto de Biologia, 72 (3), 303-307.

CLSI - Clinical and Laboratory Standards Institute. Performance standards for antimicrobial disk susceptible tests; Approved standard - Eleventh Edition. (2012). CLSI document M02-A11. Wayne, Pennsylvania.

Costa Leite, P. R. de S. da., Mendes, F. R., Pereira, M. L. R., Lima, H. J. D’A., \& Lacerda, M. J. R. (2012). Aditivos fitogênicos em rações de frangos. Enciclopédia Biosfera, Centro Científico Conhecer, 8 (15), 09-26.

Dantas, J., Leal, E., Mapossa, A. B., Silva, A. S., \& Costa, A. C. F. M. (2016). Síntese, caracterização e performance catalítica de nanoferritas mistas submetidas a reação de transesterificação e esterificação via rota metílica e etílica para biodiesel. Revista Matéria, 21 (4) ,1080-1093. https://doi.org/10.1590/S1517707620160004.0099 .

Divya, M. J., Sowmia, C., Joona, K., \& Dhanya, K. P. (2013). Synthesis of zinc oxide nanoparticle from Hibiscus rosa-sinensis leaf extract and investigation of its antimicrobial activity. Research Journal of Pharmaceutical, Biological and Chemical, 4 (2), 1137-1142.

Dobrucka, R., \& Dugaszewska, J. (2016). Biosynthesis and antibacterial activity of ZnO nanoparticles using Trifolium pratense flower extract. Saudi Journal of Biological Sciences. 23 (4), 517-523. https://doi.org/10.1016/j.sjbs.2015.05.016.

Doumbia, A. S., Vezin, H., Ferreira, M., Campagne, C., \& Devaux, E. (2015). Studies of Polylactide/Zinc Oxide Nanocomposites: Influence of Surface Treatment on Zinc Oxide Antibacterial Activities in Textile Nanocomposites. Journal of Applied Polymer Science, 132 (17). https://doi.org/10.1002/app.41776.

El Asbahani, A., Miladi, K., Badri, W., Sala, M., Ait Addi, E. H., Casabianca, H., El Mousadik, A., Hartman, D., Jilale, A., Reunad, F. N. R., \& Elaissari, A. (2015). Essential oils: From extraction to encapsulation. International Journal of Pharmaceutics, 483, 220-243. https://doi.org/10.1016/j.ijpharm.2014.12.069.

Emamifar, A., \& Mohammadizadeh, M. Preparation and Application of LDPE/ZnO Nanocomposites for Extending Shelf Life of Fresh Strawberries. Food Technology and Biotechnology, 53, 488-495. https://doi: 10.17113/ftb.53.04.15.3817

Embrapa, Empresa Brasileira de Pesquisa Agropecuária. (2018). Visão 2030: o futuro da agricultura brasileira. Embrapa.

Esmailzadeh, H., Sangpour, P., Shahraz, F., Hejazi, J., \& Khaksar, R. (2016). Effect of nanocomposite packaging containing ZnO on growth of Bacillus subtilis and Enterobacter aerogenes. Materials Science and Engineering C. 58, 1058-1063. https://doi.org/10.1016/j.msec.2015.09.078.

Espitia, P. J. P., Soares, N. F. F., Coimbra, J. S. R., Andrade, N. J., Cruz, R. S., \& Medeiros, E. A. A. (2012). Zinc oxide nanoparticles: synthesis, antimicrobial activity and food packaging applications. Food and bioprocess technology, 5 (5), 1447-1464.

Espitia, P. J. P., Soares, N. F. F., Teófilo, R. F., Vitor, D. M., Coimbra, J. S. R., Andrade, N. Souza, F. B., Sinisterra, R. D., \& Medeiros, E. A. A. (2013). Optimized dispersion of $\mathrm{ZnO}$ nanoparticles and antimicrobial activity against foodborne pathogens and spoilage microorganisms. Journal of Nanoparticle Research, 15, 1324-1340.

European Commission. (2012). Second Regulatory Review on Nanomaterials. Communication from the commission to the european parliament, the council and the european economic and social committee, p. 1-15. http://ec.europa.eu/research/industrial_technologies/pdf/policy/communication-from-the-commissionsecond-regulatory-review-on-nanomaterials_en.pdf.

FDA (2014). Part 182 - Substances generally recognized as safe. Food and drug administration, Washington DC, USA. http://www.accessdata.fda.gov/scripts/cdrh/cfdocs/cfcfr/CFRSearch.cfm?fr=182.8991.

Hu Y., \& Chen H. J. (2008). Preparation and characterization of nanocrystalline ZnO particles from a hydrothermal process. Journal of Nanoparticle Research, 10, 401-407. http://dx. 10.1007/s11051-007-9264-0

Internacional Organization for Standardization. (2007). ISO 22196 - Plastics - Measurement of antibacterial activity on plastics surfaces. USA.

Internacional Organization for Standardization. (2013). ISO 4833 - Microbiology of food and animal feeding stuffs - Horizontal method for the enumeration of microorganisms. USA.

Internacional Organization for Standardization. (2013). ISO 7218 - Microbiology of food and animal feeding stuffs - general requiriments and guidance for microbiological examinations. USA.

Jalal, R., Goharshadi, E. K., Abareshi, M., Moosavi, M., Yousefi, A., \& Nancarrow, P. (2010). ZnO nanofluids: green synthesis, characterization and antibacterial activity. Materials Chemistry and Physics, 121 (1-2), 198-201. https://doi.org/10.1016/j.matchemphys.2010.01.020.

Janaki, A. C., Sailatha, E., \& Gunasekaran, S. (2015). Synthesis, characteristics and antimicrobial activity of ZnO nanoparticles. Spectrochimica Acta Part A: Spectroscopy Molecular and Biomolecular, 5, 17-22. http://dx. doi.org/10.1016/j.saa.2015.02.041.

JIS Z 2801:2010. Antibacterial products - Test for antibacterial activity and efficacy. 
Kasemets, K., Ivask, A., Dubourguier, H. C., \& Kahru, A. (2009). Toxicity of nanoparticles ZnO, CuO and TiO2 to yeast Saccharomyces cerevisiae. Toxicology in Vitro, 23 (6), 1116-1122. 10.1016/j.tiv.2009.05.015.

Khezerlou, A., Sani, M. A., Lalabadi, M. A., \& Ehsani, A. (2018). Nanoparticles and their antimicrobial properties against pathogens including bacteria, fungi, parasites and viroses. Microbial Pathogenesis, 123, 505-526. 10.1016/j.micpath.2018.08.008

Khodja, S., Touam, T., Chelouche, A., Boudjouan, F., Djouadi, D., Hadjoub, Z., Fischer, A., \& Boudrioua, A. (2014). Effects of stabilizer ratio on structural, morphological, optical and waveguide properties of $\mathrm{ZnO}$ nano-structured thin films by a sol-gel process. Superlattices and microstructures, 75, 485-495. http://dx. doi.org/10.1016/j.spmi.2014.08.010.

Kirschner, M. R. C., Rippel, T., Ternus, R. Z. Duarte, G. W., Riella, H. G., Dal Magro, J., Mello, J. M. M., Silva, L. L., \& Fiori, M. A. (2017). Antibacterial polyamide obtained by the incorporation of glass microparticles doped with ionic zinc and by zinc oxide nanoparticle: Evaluation with Salmonella typhimurium and Staphylococcus aureus. Journal of applied polymer science, 134 (26), 1-11. https://doi.org/10.1002/app.45005.

Maciel, M. J., Machado, G., \& Avancini, C. A. M. (2019). Investigação da resistência a antibióticos e a desinfetantes de Salmonella spp. isoladas em produtos e matéria-prima de origem animal (suínos e aves). Revista Brasileira de Saúde e Produção Animal, 20, 1-13.

Mirza, E. H., Ibrahim, W. M. A. B. W., Murphy, B. P., \& Djordjevic, I. (2015) Polyoctanediol citrate-zinc oxide nano-composite multifunctional tissue engineering scaffolds with anti-bacterial properties. Digest Journal of Nanomaterials and Biostructures, 10, 415-428.

Moezzi, A., Mcdonagh, A. M., \& Cortie, M. B. (2012). Zinc oxide particles: Synthesis, properties and applications. Chemical Engineering Journal, 185-186, 122. http://dx. doi.org/10.1016/j.cej.2012.01.076.

Muñoz-Bonilla, A., \& Fernández-García, M. (2012). Polymeric materials with antimicrobial activity. Progress in Polymer Science, 37, 281-339. https://doi.org/10.1016/j.progpolymsci.2011.08.005.

Nafchi, A. M., Alias, A. K., Mahmud, S., \& Robal, M. (2012). Antimicrobial, rheological, and physicochemical properties of sago starch films filled with nanorod-rich zinc oxide. Journal of Food Engineering, 113 (4), 511-519. http://dx. doi.org/10.1016/j.jfoodeng.2012.07.017.

OECD/FAO. (2016). OECD-FAO Agricultural Outlook 2016-2025. https://doi.org/10.1787/agr_outlook-2017-en.

Oliveira, A. F., Frazzon, P.G, Brandelli, A., \& Tondo, E. C. (2007). Use of PCR-ribotyping, RAPD, and antimicrobial resistance for typing of Salmonella enteritidis involved in food-borne outbreaks in Southern Brazil. Journal of Infection in Developing Countries, 1 (2), 170-176.

Pasquet, J., Chevalier, Y., Couval, E., Bouvier, D., Noizet, G., Morlière, C., \& Bolzingerb, M. (2014). Antimicrobial activity of zinc oxide particles on five micro-organisms of the Challenge Tests related to their physicochemical properties. International Journal of Pharmaceutics, 460 (1-2), 92- 100. http://dx. Doi.org/ 10.1016/j.ijpharm.2013.10.031

Pereira A. S., Shitsuka, D. M., Parreira, F. J., \& Shitsuka, R. (2018). Metodologia da pesquisa científica. UFSM.

Perez, F. S., Bertagnolli, S. M. M, Alves, M. P., \& Penna, N. G. (2012). Nanotecnologia: aplicações na área de alimentos. Disciplinarum Scientia. Ciências da Saúde, 13 (1), 1-14.

Petchwattana A. N., Covavisaruch, B. C. S., Wibooranawong, C. S., \& Naknaen, D. P. (2016). Antimicrobial food packaging prepared from poly (butylene succinate) and zinc oxide. Measurement, 93, 442-448. https://doi.org/10.1016/j.measurement.2016.07.048.

Piletti, R., Zanetti, M., Jung, G., Mello, J. M. M., Dalcanton, F., Soares, C., Riella, H. G., \& Fiori, M. A. (2019). Microencapsulation of garlic oil by $\beta$-cyclodextrin as a thermal protection method for antibacterial action. Materials Science and Engineering C: Materials for Biological Applications, 1 (94), 139149. 10.1016/j.msec.2018.09.037.

Porto, R. C. T., Uchôa, P. Z., Peschel, L. T., Justi, B., Koslowski, L. A. D., \& Nogueira, A. L. (2017). Nanopartículas de óxido de zinco sintetizadas pelo método poliol: caracterização e avaliação da atividade antibacteriana. Matéria, 22 (1), 1-8. https://doi.org/10.1590/S1517-707620170005.0248.

Radziejewska, R. C., Stuper, K., \& Szablewski, T. (2013). Microflora and mycotoxin contamination in poultry feed mixtures from western Poland. Annals of Agricultural and Environmental Medicine, 20 (1), 30-35.

Rana, S. B., \& Singh, R. P. P. (2016). Investigation of structural, optical, magnetic properties and antibacterial activity of Ni-doped zinc oxide nanoparticles. Journal of Materials Science: Materials in Electronics, 27 (9), 9346-9355. http://dx.doi.org/10.1007/s10854-016-4975-6.

Rossi, M., Cubadda, F., Dini, L., \& Passeri, D. (2014). Scientific basis of nanotechnology, implications for the food sector and future trends. Trends in Food Science and Technology, 40, 127-148. http://dx. doi.org/10.1016/j.tifs.2014.09.004.

Sahin, E., Musevi, S. J., \& Aslani, A. (2017). Antibacterial activity against Escherichia coli and characterization of $\mathrm{ZnO}$ and $\mathrm{ZnO}-\mathrm{Al} 2 \mathrm{O} 3$ mixed oxide nanoparticles. Arabian Journal of Chemistry, 10 (1), 230-235. . http://dx. doi.org/10.1016/j.arabjc.2012.07.027.

Sekhon, B. S. (2014). Nanotechnology in agri-food production: an overview. Nanotechnology, Science and Applications, 7, 31-53. http://dx.doi.org/ 10.2147/NSA.S39406.

Sharma, V., Singh, P., Pandey, A. K., \& Dhawan, A. (2012). Induction of oxidative stress, DNA damage and apoptosis in mouse liver after sub-acute oral exposure to zinc oxide nanoparticles. Mutation Research, 745 (1-2), 84-91. http://dx.doi.org/10.1016/j.mrgentox.2011.12.009.

Shoja, M., Shameli, K., Ahmad, M. B., \& Kalantari, K. (2015). Preparation, characterization and antibacterial properties of polycaprolactone/zno microcomposites. Digest Journal of Nanomaterials and Biostructures, 10 (1), 169-178.

Sirelkhatim, A., Mahmud, S., Seeni, A., Kaus, N. H. M., Ann, L. C., Bakhori, S. K. M., Hasan, H., \& Mohamad, D. (2015). Review on zinc oxide nanoparticles: antibacterial activity and toxicity mechanism. Nano-Micro Letters, 7 (3), 219-242. https://doi.org/10.1007/s40820-015-0040-x. 
Souza Santana, E., Mendes, F. R., Barnabé, A. C. de S., Oliveira, F. H. de, \& Andrade, M. A. (2011). Uso de produtos alternativos aos antimicrobianos na avicultura. Enciclopédia Biosfera, Centro Científico Conhecer, 7 (13), 985- 1009.

Strockbine, N. A., Bopp, C. A., Fields, P. I., Kaper, J. B., \& Nataro, J. P. (2015). Escherichia, Shigella, and Salmonella. In: Jorgensen JH, Pfaller MA (EE.). Manual of clinical microbiology. (11a ed.), Washington: ASM Press, 685-713.

Sung, S. Y., Sin, L. T., Tee, T. T., Bee, S. T., Rahmat, A. R., Rahman, W. A. W. A., Tan, A. C., \& Vikhraman, M. (2013). Antimicrobial agents for food packaging applications. Trends in Food Science \& Technology, 33, 110-123. https://doi.org/10.1016/j.tifs.2013.08.001.

Thaya, R., Malaikozhundan, B., Vijayakumar, S., Sivakamavalli, J., Jeyasekar, R., Shanthi, S., Vaseeharan, B., Ramasamy, P., \& Sonawane, A. (2016). Chitosan coated $\mathrm{Ag} / \mathrm{ZnO}$ nanocomposite and their antibiofilm, antifungal and cytotoxic effects on murine macrophages. Microbial Pathogenesis, 100, 124-132. 10.1016/j.micpath.2016.09.010.

Tozzo, K., Américo, F.G., Neto, K. M., Spercoski, M. R., Soares, V. M., \& Bersot, L. S. (2018). Migration of Salmonella serotypes Heidelberg and Enteritidis in previously frozen chicken breast meat. Food Microbiology, 69, 204-211. http://dx.doi: 10.1016/j.fm.2017.07.021.

Webber, B., Borges, K. A., Furian, T. Q., Rizzo, N. N., Tondo, E. C., Santos, L. R. dos., Rodrigues, L. B., \& Nascimento, V. P. do. (2019). Detection of virulence genes in Salmonella Heidelberg isolated from chicken carcasses. Revista do Instituto de Medicina Tropical de São Paulo, 61, 1-7. http://dx.doi.org/10.1590/s1678-9946201961036.

Xiang, Y., Li, J., Liu, X., Cui, Z., Yang, X., Yeung, K. W. K., \& Shuilin, H. P. (2017). Construction of poly (lactic-co-glycolic acid)/ZnO nanorods/Ag nanoparticles hybrid coating on Ti implants for enhanced antibacterial activity and biocompatibility. Materials Science and Engineering, 79, 629-637. 10.1016/j.msec.2017.05.115.

Xie, Y., He, Y., Irwin, P. L., Jin, T., \& Shi, X. (2011). Antibacterial activity and mechanism of action of zinc oxide nanoparticles against Campylobacter jejuni. Appliedand environmental microbiology, 77 (7), 2325-2331. http://dx. doi.org/10.1128/AEM.02149-10.

Yamamoto, O. (2001). Influence of particle size on the antibacterial activity of zinc oxide. International Journal of Inorganic Materials, 3, 643-646. http://dx. doi.org/10.1016/S1466-6049(01)00197-0.

Youssef, A. M., \& El-Sayed, S. M. Bionanocomposites materials for food packaging applications: Concepts and future outlook. Carbohydrate Polymers, 193, 19-27. 10.1016/j.carbpol.2018.03.088.

Zanetti, M., Mello, J. M. M., Dalcanton, F., Ternus, R. Z., Riella, H. G., Araujo, P. H. H., \& Fiori, M. A. (2015). Microbiological characterization of pure geraniol and comparison with bactericidal activity of the cinnamic acid in Gram-positive and Gram-negative bacteria. Journal of Microbial \& Biochemical Technology, 7, 186-193. 10.4172/1948-5948.1000203. 